\title{
MANAGEMENT OF BUSINESS INFORMATICS MODEL - PRINCIPLES AND PRACTICES
}

\author{
Jiří Voříšek, Jan Pour, Alena Buchalcevová
}

\section{Introduction}

This paper describes the characteristics and principles of the $\mathrm{MBI}$ (Management of Business Informatics) model developed at the Department of Information Technologies, University of Economics in Prague. The aim of the MBI model is to offer IT professionals in charge of information technology management in organizations a comprehensive methodological support based on industry best practices. An application of this model brings along the potential to increase an overall IT effectiveness, improve IT governance and IT services efficiency, and furthermore result in a better business performance. The MBI model comprises important relationships and attributes relevant to information systems management and in addition provides a suitable methodological basis for university courses focused on Business Informatics and IT Project Management. The paper is organized as follows. Firstly, current issues in Business Informatics Management are described in section 1 followed by an overview of a present status in the Czech Republic. Section 2 introduces a concept of the MBI model including its principles and meta-model. Further, various model types within the $\mathrm{MBI}$ area are presented in section 3. Section 4 then outlines a pilot application of the MBI model. Lastly, concluding remarks and future research are presented.

\section{Current Issues in Business Informatics}

Information Systems (IS) is a scientific discipline with a global reach that investigates a development, use, and impact of information and communication technologies (ICT). Business Informatics (BI) as such constitutes a major scientific community within the IS discipline according to [7]. Business Informatics currently represents a dominant IS community within the German-speaking countries (Austria, Germany, Switzerland) and is best characterized by its strong connection to industry especially focused on engineering [7].

Management of business informatics has been in the spotlight of researchers and IT practitioners from all over the world for a number of decades. However, a rising complexity and heterogeneity of technological infrastructure and enterprise applications together with the growing possibilities of information service provision have contributed to a demanding management of business informatics. In particular, diverse options of IT service provision, i.e. except standard outsourcing of selected applications and services also various cloud computing models such as Software as a Service (SaaS), Platform as a Service (PaaS) and Infrastructure as a Service (laaS), significantly increase the number of stakeholders and business relationships a company may have. Nowadays, company management expects an improved effectiveness and reduced costs associated with IT services provision forcing IT executives to seek better methods for business informatics management. Such a need to improve quality of business informatics management has led to a development of numerous approaches. We discuss these approaches and the challenges organizations face in their implementation in the following section.

\subsection{Existing Approaches to Management of Business Informatics}

Increasing requirements on the extent and quality of business informatics management have resulted in a development of various methodologies, models, frameworks and standards and also their further application 
in practice. To such methodological base primarily belong COBIT [11], CMMI [20], ISO/IEC 20000 [9], [10], ITIL [24] and TOGAF [15] that are mostly process-oriented approaches. These methodological sources represent current best practices and include recommendations addressing various IT management issues encountered in practice. Their detailed comparison is presented in [5], [21], [25], [26]. However, their application in practice brings along numerous problems. A recent survey among Czech organizations [28] has indicated a relatively low adoption level of methodologies applied within business informatics management, and also an overall perception their benefits are significantly limited. Considering ITIL being the most broadly applied methodology worldwide, it is utilized by $53 \%$ of Czech companies. However, only approximately $6 \%$ of them have ITIL fully implemented. In the case of COBIT, $53 \%$ of respondents do not utilize COBIT within their organizations at all. On the other hand, 12\% of Czech companies apply this methodology exclusively for strategic IT management. According to survey respondents, to the most significant reasons for the low level of methodology utilization belong their complexity, excessive cost associated with their implementation, and considerable requirements on IT practitioners and their professional qualification even in the case of SMEs (Small and Medium-sized Enterprises).

A current trend in business informatics is to strengthen the use of strategic applications, i.e., enterprise applications that have a potential to deliver a competitive advantage. Such strategic applications include Business Intelligence $(\mathrm{BI})$, Competitive Intelligence $(\mathrm{CI})$, Customer Relationship Management (CRM) (in particular social CRM), and various forms of electronic and mobile business applications [12]. Their implementation is quite common in multinational corporations. However, SMEs face significant problems while implementing such applications because of limited financial and human resources, as stated e.g. by Molnár [13]. On top of that, IT management in these enterprises is distinguished by a number of specific features which are in detail described by Antlová et al. [1]

Further, IT professionals discuss the application of metrics in business informatics especially in relation to the processes of business informatics management, and also their integration with IT performance management methods. According to [2] and [26], performance management of business informatics represents one of the most important areas where business informatics and performance management principles are applied in practice. However, we need to differentiate between performance management in organizations that provide IT services (i.e. IT service providers) and performance management in organizations that are not service providers (i.e. consumers of IT services) [25], [26]. IT service providers tend to focus on an effective delivery of IT services that maximize their profit, while IT departments of organizations consuming IT services are focused rather on securing the availability of all IT services used by various business units. Thus, it is important to consider a relevant composition of indicators for measuring and evaluating process performance quality, as Šimonová [23] points out.

The role of IT executives such as Chief Information Officers (ClOs) in ensuring a continuous development and innovation of both IT applications and IT infrastructure represents quite an important issue of business informatics related to a harmonization of technology innovation with organization's business needs. IT leadership issues comprising a suitable allocation of responsibility and authority in relation to IT, effective use of human resources, and IT effectiveness monitoring and evaluating are extensively covered in [3], [8], [14], [21], [22], [26], [27].

A key challenge of business informatics management consists in a creation of a single universal model applicable across different types of organizations. Many researchers and practitioners argue that each organization needs to develop its own model for management of business informatics that meets its specific requirements. Our surveys (see section 1.2) as well as international studies, e.g. Weill and Ross [27], confirm such statements since IT executives tend to develop specific management models adapted to a particular environment an organization operates in. Among factors influencing the organization's environment are industry sector, organization size, corporate culture, employees' skills and knowledge, legislative environment, and IT services available at acceptable quality and price. 
Overall, business informatics management is affected by a number of issues, including e.g. potential risks associated with IT operation and innovation as stated by Kozel et al. [12],

An identification and further analysis of the above mentioned issues and other challenges related to management of business informatics determine the objectives and principles of the Management of Business Informatics (MBI) model. The $\mathrm{MBI}$ model was designed on the basis of several surveys conducted among Czech organizations during the period of 2010-2012. A thorough analysis of obtained results is described in the following section.

\subsection{Results of IT Management Surveys in the Czech Republic}

Business informatics in Czech enterprises as well as in institutions of public administration has undergonea very dynamic development in recent years, in particular in terms of technological innovation. However, international comparisons show that in the Czech Republic business informatics performance suffers from a number of unresolved issues and unexploited potential [14], [25]. According to international statistics, the Czech Republic ranges still under the EU-27 average in the application of e-business and e-government, and also in the use of electronic information resources [28]. While there exist a number of factors contributing to such status, quality of information systems management plays a key role. To substantiate this assertion, we conducted several major surveys involving 1,400 respondents from Czech enterprises as well as institutions of public administration during the period of 2010-2012. Detailed analyses of the survey results were published in [6], [14], [18], [25], [26].

The most important survey was conducted in 2010 among 600 respondents in the Czech Republic. This survey was primarily focused on business informatics management, different approaches to its innovation and economic issues related to business informatics. Regarding the composition of respondents, medium-sized companies constituted with $63 \%$ the largest group of respondents, while small and large enterprises participated in the survey practically equally (17, resp. $20 \%$ ). To classify the respondents into particular sectors, we applied the Industrial Classification of Economic Activities (OKEČ). Institutions of public administration represented with $19 \%$ the largest group of respondents. On the contrary, mining industry comprised only a negligible group of respondents reaching $0.5 \%$. All other sectors were represented quite evenly ranging from 3 to $8 \%$. The vast majority $(81 \%)$ of respondents constituted Czech companies followed by companies within multinational corporations (13\%). Czech enterprises with foreign subsidiaries accounted for the remaining $5.5 \%$. A broad description of these survey results is presented in [18]. Below we summarize just the most important conclusions that were used as inputs into the MBI model:

- main objectives of business informatics management were confirmed, i.e. a maximum support for business activities, the highest possible alignment level of business needs and business informatics functions (Business/IT alignment),

- company's approach to business informatics management needs to consider all external and internal factors affecting an organization,

- management of business informatics should follow appropriate standards, methodologies and methods and apply suitable metrics to determine the quality and performance of management processes; necessary documentation and expertise should be ensured,

- information systems need to be developed and operated at reasonable costs that correspond to the role of IT within an enterprise; e.g. minimizing IT costs may not be the best long-term strategy,

- monitoring existing applications' and new projects' potential and real effects is essential for an organization especially with a primary focus on strategic impact delivering a competitive advantage,

- company's strategic applications that are critical for increasing its competitiveness need to be identified and given an investment priority,

- innovation in business informatics should follow IT market development and also current IT status of business partners and competitors,

- cooperation between user departments, IT departments and external providers should be based on service contracts and service level agreements (SLAs),

- while ensuring necessary resources, it is essential to choose such an operational 
model (outsourcing, cloud computing, etc.) that delivers cost savings at an acceptable level of risk,

- required level of technology security and reliability needs to be assured at a reasonable cost,

- required qualification of users and IT practitioners should be developed systematically,

- company's management should take into account a probable shortage of IT specialists over the next few years.

\section{Management of Business Informatics Model}

The Management of Business Informatics (MBI) model was developed at the Department of Information Technologies, University of Economics in Prague and described in detail in [23]. The MBI model was defined based on the results of IT management surveys, an extensive literature review, analysis of existing standards, methods and frameworks as well as generalized knowledge gained from numerous consulting projects across a wide spectrum of organizations.

\subsection{MBI Model Objectives and Principles}

The primary objective of the $\mathrm{MBI}$ model is to provide a support for IT management activities in companies that figure as users of IT services. The MBI model provides a consistent and flexible business informatics management methodology that incorporates the best practice guidelines for specific industry domains. The model helps IT practitioners to:

- document and analyze an existing system of business informatics management,

- design and implement a new (improved) management system,

- obtain an advice and best practice solutions for specific IT management issues such as: How to develop an information strategy? How to prepare IT budget? What is the concrete structure and content of SLA for application services delivered in the form of Software as a Service?

The MBI model helps organizations to improve the performance of enterprise IT systems more specifically the quality, availability, security and effectiveness of IT services, and indirectly the overall business performance [19].

To address such requirements, the following key principles of the MBI model were defined:

1. The model supports an organization's business strategy in defining strategic applications of business informatics as well as in monitoring IT investment profitability [11], [24], [25].

2. The model allows a control of all key features of enterprise information system [21], [25]:

- Required functionality inclusion,

- Availability, Timeliness, Accuracy and Trustworthiness of required functions and information,

- Compliance with legislations,

- Reliability,

- User-friendliness,

- Security,

- Flexibility,

- Openness,

- Integrity,

- Standardization,

- Performance,

- Effectiveness.

3. The model records all responsibilities and authorities within an organization in the context of business informatics [27].

4. Business informatics management is based on a coherent system of metrics that evaluate all important IT services, IT processes and IT resources [16], [25].

5. The model provides various levels of detail (granularity) of management tasks and metrics that correspond to the requirements of different organization types.

6. The model rapidly responds to changing needs of business informatics, its content and functionality is easily extendable and upgradable.

7. The application of $\mathrm{MBI}$ model in practice offers a high flexibility. Implementation of individual model components (tasks) is supported without having to implement the entire model. Considering a significant effort involved in a comprehensive business informatics system implementation, it is often more effective to address only those areas identified as the most problematic, or with the highest impact on an enterprise performance and its success. 
8. The model is effectively deployable in organizations of a different size and operating in different industry sectors. Model implementation respects specific conditions under which an organization operates including its financial and human resources allowing a successful application of the model in SMEs that typically have limited financial and human resources.

9. An integral part of the model contains recommendations summarizing relevant practical experiences.

\subsection{MBI Model Concept}

With the aim of a clear definition, uniform understanding and possibility of enhancement, the $\mathrm{MBI}$ meta-model was defined. Figure 1 shows the meta-model that represents the MBI classes of objects and types of relationships between them. The MBI meta-model is presented in the UML 2.0 class diagram notation.

A task is a key MBI component that represents a basic business informatics management unit. Task describes how to proceed in solving a particular management problem. Concrete tasks represent e.g. Proposal for Enterprise IT System Sourcing, IT Service Implementation, IT Service Activation, Security Audit Implementation etc. The MBI model defines a large number of tasks that are organized in a three-level hierarchy as illustrated in Figure 2.

\section{Fig. 1: The MBI Meta-model}

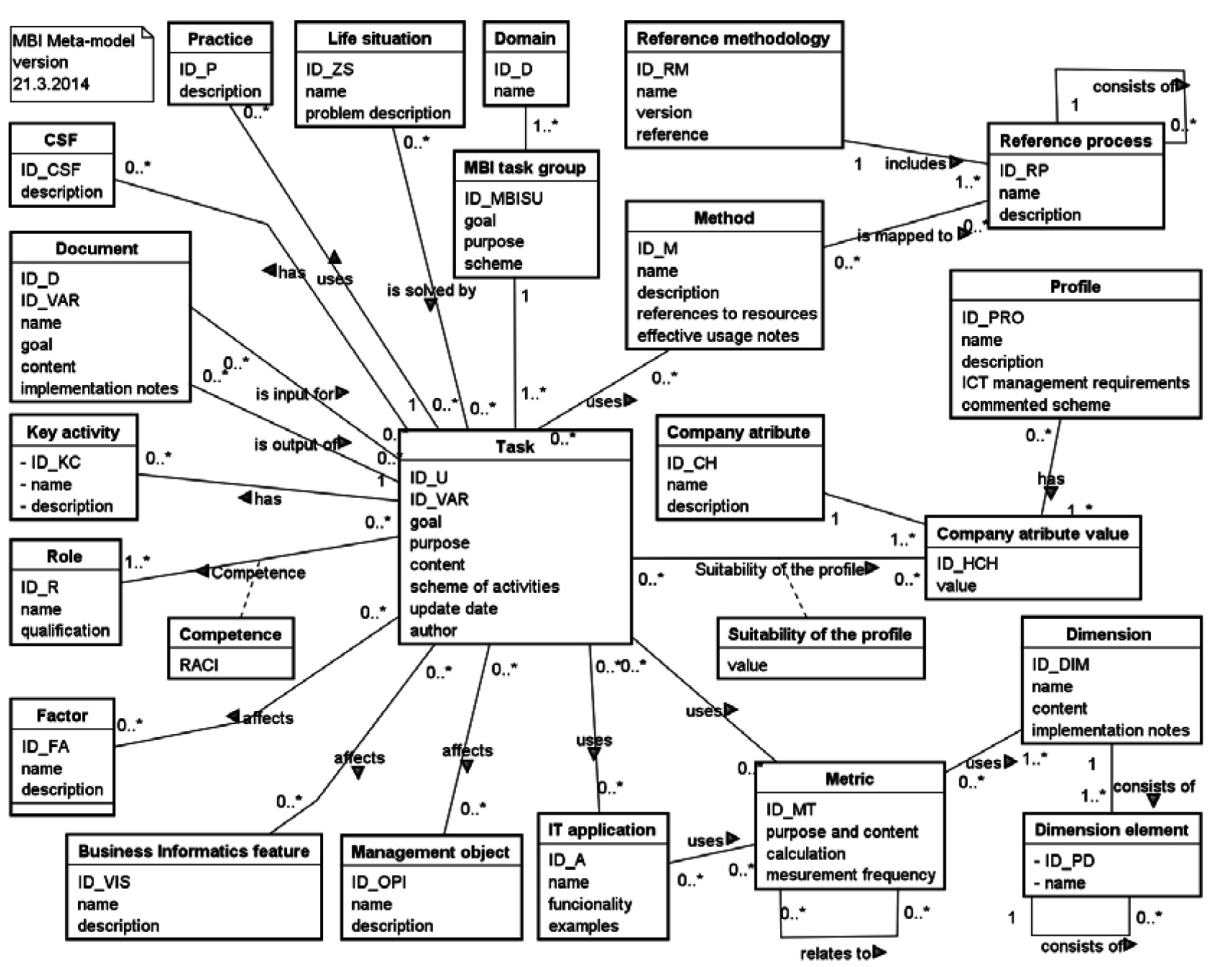




\section{Fig. 2: Hierarchical structure of tasks in the MBI model}

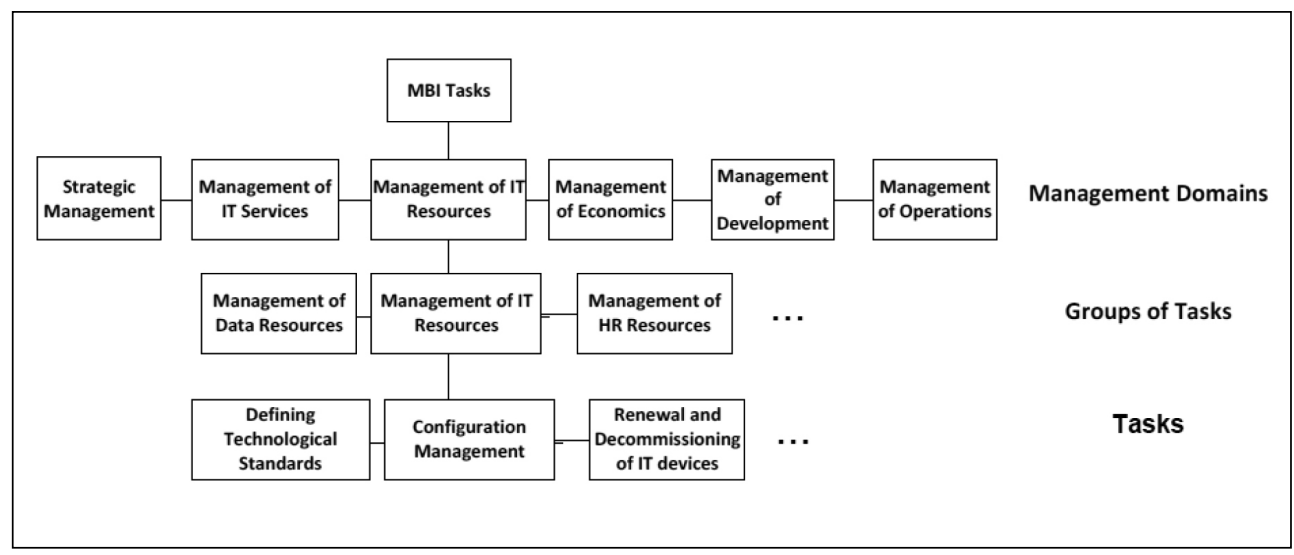

Source: own

The Management Domains level constitutes the highest level of the MBI hierarchy and consists of the following domains: Strategic Management, Management of IT Services, Management of IT Resources, Management of IT Economics, Management of IT Development, and Management of IT Operations. Within each management domain Groups of Tasks are defined, which represent a set of related tasks.

Each task has several attributes. Some of them, i.e. ID, ID of a task variant, author and update date are used for identification purposes. Task can be defined in variants. A variant of the task describes specifics of a task realization in various conditions according to an organization size, industry sector or organization type. Besides the identification attributes, there exist also other attributes which represent a specific content of the task, i.e. goal, purpose, content. Task comprises activities that are expressed in the form of activity scheme at various levels of granularity (i.e. only core activities, highlevel process diagram, or detailed process diagram) depending on the requirements a particular problem demands. On one hand, this enables a precise description of the task, and on the other hand, it leaves an initiative on IT staff as recommended by the Knowledge Based Process Reengineering Method [26]. Overall, tasks constitute the basis for a metric specification as described in [15].
Relationships to other classes represent the additional task content. These relationships enable to refer to the content used in multiple tasks or to multiple occurrences in the relationship. To the most important task related classes belong the following:

- Documents - this class includes printed or electronic documents used as task inputs or outputs. A document is either a tool of business informatics management (e.g. project plan, project objectives), or provides a solution to a particular problem (e.g. test scenario, tender document for selection of an IT service provider).

- Scenarios - this class represents typical issues that need to be addressed in a business life. For example considering IT cost reduction to be the requirement, the $\mathrm{MBI}$ model identifies tasks, documents and metrics that relate to IT costs and provides recommendations to achieve such cost reduction.

- Applications - this class comprises application software that can be utilized for a given task [25].

- Metrics - this class includes metrics expressed on the basis of dimensional modeling, i.e. as indicators and their analytical dimensions. Metrics determine the Key Performance Indicators (KPI) or Key Goal Indicator $(\mathrm{KGI})$ of tasks. Considering 


\section{Fig. 3: "Doors" into the MBI model for a specific issue}

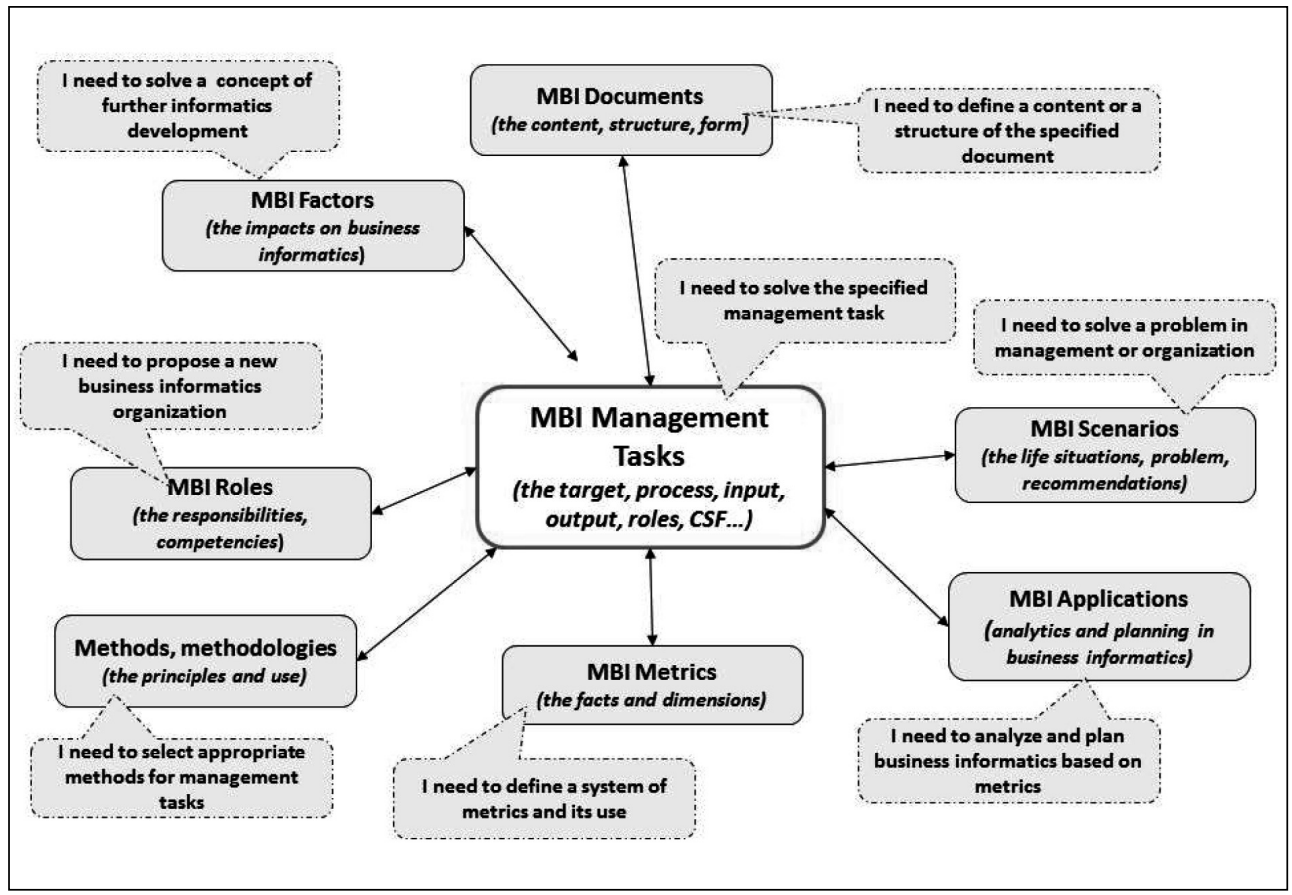

for example "IT operating costs" that have the dimension of IT services, IT applications, or individual business units, metrics can provide information such as "What are the operating costs of a particular service for individual business units." Matching metrics to their individual business processes in the context of tasks ensures that only metrics that are useful in practice are defined. Data sources for metrics measurement need to be available and accessible within a company, so that costs of obtaining such data do not exceed the benefits of their use [26].

- Methods - this class describes formalized processes and guidelines to fulfilling the goal of the task. Practices represent recommended management practices that can be used to accomplish particular tasks.

- Roles - this class expresses specific responsibilities of a role holder. Such roles include: $\mathrm{ClO}$, Operations Manager, Project Manager, IT Architect etc. Roles are linked to individual tasks using the responsibility assignment matrix (RACl) format applying the four key responsibilities: Responsible, Accountable, Consulted, and Informed.

- Factors - this class has a significant impact on the way a particular task is performed. To the most important factors belong: Organization Size, Industry Sector (in which an organization operates) and Organization Type (i.e. private company or public institution). Considering the example of the factor Organization Type together with the task Preparation of a Tender for the Supply of IT Services, the solution of the problem for a public institution is completely different than in the case of a private company. The reason is the legislation which has to be followed in the case of public institution.

These seven classes related to the task represent the so called "doors" in the MBI model (Fig. 3). Such doors allow a direct access 
to information. Thus, a user does not need to go through the entire model, but is able to select a particular role or some other path relevant to an issue he is working on.

In order to assure that key features of business informatics are considered within the model, a concept of Business Informatics Features was introduced. For each task an impact on business informatics features is recorded in the form of yes/no answer. This way it is possible to discover all tasks that affect a particular business informatics feature. In the initial settings of the MBI model the following Business Informatics Features are defined:

- Functionality,

- Availability, Timeliness, Accuracy and
Trustworthiness of required functions and information,

- Compliance with legislations,

- Reliability,

- User-friendliness,

- Security,

- Flexibility,

- Openness,

- Integrity,

- Standardization,

- Performance,

- Effectiveness.

\section{MBI Model Types}

As noted in section 1, it is not possible to use a single optimal model of business informatics

\section{Fig. 4: MBI model types}

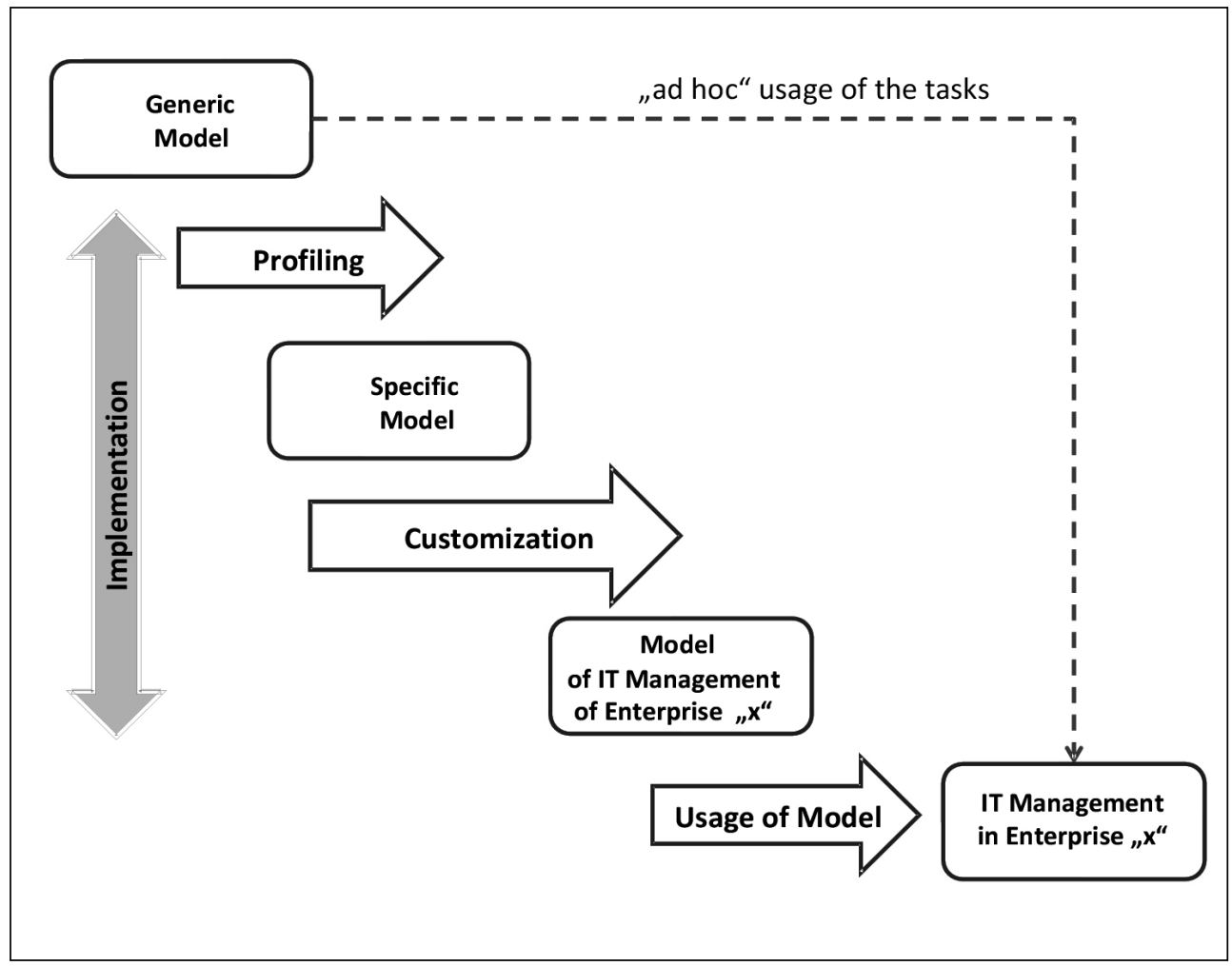


management across all organizations. The MBI model includes several model types that differ in the level of adaptation to specific circumstances of a given organization type.

The most comprehensive and general model represents the $\mathrm{MBI}$ Generic model. The Generic model is intended for all types of organizations and includes generalized best practice guidelines for business informatics management and their specific variants of different business informatics management factors. The MBI Generic model captures also proven management practices and practical experiences in the form of tasks, documents, methods, metrics and other objects as described in section 2.2.

The second type of the MBI model, i.e. the $\mathrm{MBI}$ Specific model, is aimed at organizations that belong to a particular sector of the economy (automotive, banking, public administration, etc.). The content of the Specific model is adapted to particular industry, business, legislative and other conditions that apply to a given sector of the economy. The MBI Specific model is created during the profiling process, when certain variants of MBI tasks and documents relevant for a specific sector of the economy are selected (see Figure 4).

The third type of the MBI model, i.e. the Model of IT Management of Enterprise " $X$ " is intended for a concrete organization. The model is created by customizing the MBI Specific model when taking into account particular aspects of an organization. The customization process includes:

- Selection of object occurrences from the MBI Specific model (i.e. tasks, documents, metrics, etc.) relevant to a concrete organization. This further reduces the number of each object occurrence in comparison with the Specific model eliminating those occurrences that IT management considers as irrelevant for its organization or a given situation, i.e. those that are not in line with the implementation goals of $\mathrm{MBI}$.

- Modification of objects that do not fully correspond to specific conditions of an organization. Such specific conditions may arise as a result of various business informatics factors (section 2.2), but also as a result of management efforts to set a different (from the MBI model) level of business and IT process standardization and its enforcement.
- Completion of additional tasks and related objects that are required by a concrete company but not contained in the $\mathrm{MBI}$ Specific model (i.e. capturing specific knowhow of an organization).

- Definition of IT department roles. The $\mathrm{MBI}$ Generic model assumes a core set of roles for an organization and its IT department. Each role is assigned particular responsibilities for individual MBI tasks using the RACl matrix. However, these roles can be defined in a specific organization differently, or they may be characterized by different responsibilities or authorities.

- Assignment of roles to individual tasks by modifying the RACl matrix for these tasks (determined by responsibilities and authorities of particular IT roles in an organization - employees with a given role are assigned tasks they are fully responsible for, and tasks they cooperate on).

A model application in an organization involves a use of individual tasks and their implementation by individual actors. Task outputs may be saved into the model as document templates (variants).

\section{MBI Model Application and Future Development}

There exist two alternatives of a $\mathrm{MBI}$ model application in practice. Firstly, IT executives can utilize the model to create a comprehensive system of business informatics management based on best practices in IT management (as illustrated in Fig. 4). This way the $\mathrm{MBI}$ model helps to describe all tasks, roles and their responsibilities, and other objects included within IT management. MBI then becomes a company regulation that determines who, when and how solves various IT issues in an organization.

Secondly, the MBI model offers IT executives a solution to issues occurring at strategic, tactical and operational level. The model includes template solutions to current issues that can be found through a MBI navigation mechanism based on "doors", or by searching for a specific scenario.

Example 1: A user needs to create an information strategy for his organization. If the user is only interested in the structure of an information strategy document, he locates the relevant document in the $\mathrm{MBI}$ system and uses 
it directly. If the user needs to know the entire process of strategic management, he uses these two task groups: "Strategic Analysis of Business Informatics" and "Strategic Proposal for Business Informatics".

Example 2: A user needs to prepare SLA for new IT services. Using the MBI navigation mechanism the user locates the task "Preparation and Approving of SLAs", follows the task recommendations and applies SLA templates stored in the MBI system for inspiration.

Example 3: A user identifies a problem in enterprise applications performance, i.e. applications have poor availability and slow response time. Using the $\mathrm{MBI}$ navigation mechanism the user identifies tasks that impact enterprise applications performance, in this case the task "Ensuring Operational Performance and Scalability of IT Services".

The authors expect the second alternative of model application to be primarily used by IT practitioners in SMEs, and the combination of both alternatives then in large enterprises.

The content of the MBI model is still under development and currently contains data gained from various consulting assignments and derived from literature on this topic.

\subsection{Process of MBI Model Implementation}

To ensure the implementation of a comprehensive system of business informatics management brings the desired effect (i.e. IT/ business alignment, competitiveness increase, etc.), the $\mathrm{MBI}$ implementation must be well managed and controlled. The $\mathrm{MBI}$ authors thus recommend the following implementation steps:

1. Defining the $\mathrm{MBI}$ implementation objectives of an organization and determining the metrics for their measurement (senior management). Definition of the objectives will vary depending on the current business situation and anticipated role of business informatics over the next two to three years.

2. Establishing the $\mathrm{MBI}$ implementation team. The team should have at least three members. The team leader has to be the $\mathrm{CIO}$ or another IT executive whose responsibility includes business informatics management. This executive needs to possess necessary competencies, but also have a natural authority to ensure that the fundamental changes the $\mathrm{MBI}$ implementation brings will be enforced. The second member of the team should be a business representative that together with the $\mathrm{ClO}$ participates in defining IT governance rules and other rules determining the relationship between business and informatics. The third member of the team should be technology oriented, responsible for defining technologyoriented tasks and technological aspects of the business. In the case of larger organizations, it is appropriate to add a finance department representative that will address cost and revenue aspects of the $\mathrm{MBI}$ implementation.

3. Identifying areas (groups of tasks) that business informatics needs to address including their priorities. The $\mathrm{MBI}$ implementation objectives defined in the first step constitute the input into this step. Its output represents a set of tasks implemented in the organization including their priority. The implementation team is recommended to use the $\mathrm{MBI}$ task catalog during this step.

4. Creating the $\mathrm{MBI}$ implementation plan (stage, schedule, budget).

5. Selecting the $\mathrm{MBI}$ tasks and other $\mathrm{MBI}$ objects (documents, metrics, etc.) that suit the list of tasks defined in the previous step.

6. Completing or modifying those tasks that were not successfully resolved in the previous step. IT practitioners are recommended to comply with the rules appropriate for process description and process maturity when modifying the tasks.

7. Approving the new system of business informatics management (top enterprise executives)

8. Providing training to all company employees that possess roles described in the $\mathrm{MBI}$ model. Each employee is trained in those tasks that relate to his/her role(s).

9. Starting up with the new system of business informatics management.

\subsection{MBI Model Further Development}

Considering the lack of a proven content of the $\mathrm{MBI}$ model leading to possible erroneous practices or poor decisions of the MBI model users, it is essential for the $\mathrm{MBI}$ model development to perform all the practices according to given rules that ensure its high 
quality. The quality of the model is guaranteed by the MBI Steering Committee that decides about:

- Inclusion of new object occurrences (tasks, documents, etc.) into $\mathrm{MBI}$. To ensure the quality of $\mathrm{MBI}$ content, the Steering Committee reviews each new object occurrence. Two reviewers are asked to present their opinion on such a new object occurrence. The Steering Committee then decides on its own considering the reviewers' opinion.

- Content of various MBI versions.

- Date of a new MBI version release.

In general, all tasks and other objects of the $\mathrm{MBI}$ Generic model should be regarded as recommendations that can be modified by the user organization to suit its needs. Further rule specification forming the $\mathrm{MBI}$ Specific model needs to be defined by the $\mathrm{ClO}$ and his team and be part of corporate IT Governance. When modifying the MBI model, the authors recommend to take into account factors affecting business informatics management in an organization and to choose the level of process and component description according to the KBPR (Knowledge Based Process Reengineering) method [26].

\section{Conclusions}

The $\mathrm{MBI}$ model aims to provide a business informatics management method that incorporates all relevant international experiences and at the same time respects specific conditions and customs in Czech organizations. The MBI model represents an original solution that brings along essential advantages over existing business informatics management methodologies. To such advantages primarily belong monitoring links between individual objects and the possibility to utilize these links as search criteria. Moreover, the model captures an influence of various business informatics factors on the $\mathrm{MBI}$ tasks and enables to adjust its context according to these factors. A flexible access to necessary information is provided through the concept of "doors". In addition, the MBI model metrics and analytical applications monitor IT investment effectiveness, which follows the model objectives. On top of that, the MBI model addresses the issue of harmonizing business goals with information technology by defining the group of tasks "Business/IT Alignment" and also by determining metrics that measure such goal achievement. Overall, an indirect benefit of the MBI model lies in the clarification of concepts, principles and methods used in business informatics management.

The MBI model is primarily intended for SMEs, as several studies confirmed that for these organizations the application of available large-scale methodologies (e.g. ITIL, COBIT, etc.) is too expensive and time consuming.

In its present form the MBI model is an ongoing project and represents a starting point for further development, aiming to provide a comprehensive platform for business informatics management based on precise metrics. Such trend towards more effective IT management based on measurable outcomes is evident from our recent surveys embracing a large number of Czech organizations. These studies identify the need for effective methods and tools that enable IT executives to make informed decisions based on reliable information.

The MBI model was presented at the Business Informatics Management Conference arranged by the Czech Society for Systems Integration in January 2014 and enjoyed a major success. The MBI model is available as a web application (at website mbi.vse.cz) and the $\mathrm{MBI}$ community participates on its further development. Also the association ITSMF expressed its interest in cooperation on the MBI model development.

This research was supported by the GACR (Grant Agency, Czech Republic) grant No. P403/11/0574 and the Research Centre for Human Centered Technology Design at the University of Technology, Sydney. 


\section{References}

[1] ANTLOVÁ, K., POPELÍNSKÝ, L., TANDLER, J. Long Term Growth of SME from ICT Competencies and Web Presentations. E+M Ekonomie a Management. 2011, Vol. 14, Iss. 4, pp. 125-139. ISSN 1212-3609.

[2] BACAL, R. Manager's Guide to Performance Management. New York: McGraw-Hill, 2012. ISBN 978-0-07-177225-9.

[3] DOHNAL, J., PŘÍKLENK, O. CIO a podpora byznysu. Praha: Grada, 2011. ISBN 978-80247-4050-8.

[4] DOLEJŠOVÁ, M. Rizika $v$ informačních systémech a jejich vyhodnocování. $E+M$ Ekonomie a Management. 2007, Vol. 10, Iss. 4. ISSN 1212-3609.

[5] DOUCEK, P., NOVOTNÝ, O. Standardy rízení podnikové informatiky. E+M Ekonomie a Management. 2007, Vol. 10, Iss. 3. ISSN 1212-3609.

[6] DOUCEK, P., NOVOTNÝ, O., PECÁKOVÁ, I., VOŘÍŠEK, J. Lidské zdroje v ICT - Analýza nabídky a poptávky po IT odbornících v ČR. Praha: Professional Publishing, 2007. 201 s. ISBN 978-80-86946-51-1.

[7] HEINRICH, L.J., RIEDL, R. Understanding the dominance and advocacy of the designoriented research approach in the business informatics community: a history-based examination. Journal of Information Technology. 2013, Vol. 28, Iss. 1 , pp. 34-49. ISSN 02683962. DOI: $10.1057 /$ jit.2013.1.

[8] HOLTSNIDER, B., JAFFE, B.D. IT Managener's Handbook. Amsterdam: Elsevier, 2012. ISBN 978-0-12-415949-5.

[9] ISO/IEC 20000-1:2011. Information technology -- Service management -- Part 1: Service management system requirements.

[10] ISO/IEC 20000-2:2012. Information technology -- Service management -- Part 2: Guidance on the application of service management systems.

[11] IT GOVERNANCE INSTITUTE. Cobit 5: Enabling Processes. Rolling Meadows: ISACA, 2012. ISBN 978-1-60420-241-0.

[12] KOZEL, T., MOHELSKÁ, H. Modely firem s mobilně orientovanou architekturou. $E+M$ Ekonomie a Management. 2010, Vol. 13, Iss. 4, pp. 135-142. ISSN 1212-3609.

[13] MOLNÁR, Z., STŘELKA, J. Competitive intelligence $\mathrm{v}$ malých a středních podnicích. E+M Ekonomie a Management. 2012, Vol. 15, Iss. 3, pp. 156-170. ISSN 1212-3609.
[14] NOVOTNÝ, O., VOŘíŠEK, J., et al. Digitální cesta k prosperitě. Praha: Professional Publishing, 2011. ISBN 978-80-7431-047-8.

[15] OPEN GROUP. TOGAF Version 9. The Open Group Architecture Framework. The Open Group, 2009. 778 p. ISBN 978-90-8753230-7.

[16] PALADINO, B. Innovative Corporate Performance Management: Five Key Principles to Accelerate Results. Indianopolis: Wiley Publishing, 2011. ISBN 978-0-470-62773-0.

[17] POUR, J. Business intelligence řešení v modelu MBI. Systémová integrace. 2012, Vol. 19, Iss. 2, pp. 19-31. ISSN 1210-9479.

[18] POUR, J., VOŘíŠEK, J. K výsledkům průzkumu české informatiky. Systémová integrace. 2011, Vol. 18, Iss. 1, pp. 15-34. ISSN 1210-9479.

[19] POUR, J., VOŘÍŠEK, J., FEUERLICHT, G. Model for management of enterprise IT: considerations of the impact of Cloud computing. In: Confenis - 2013. Linz: Trauner Verlag, 2013. pp. 157-168. ISBN 978-3-99033081-4.

[20] SEI. CMMI for Development, Version 1.3. Pittsburgh: Software Engineering Institute Carnegie Mellon, 2010.

[21] SCHIESSER, R. IT Systems Management. New York: Prentice Hall, 2010. ISBN 978-0-13702506-0.

[22] SCHNIEDERJANS, M.J., HAMAKER, J.L., SCHNIEDERJANS, A.M. Information Technology Investment: Decision-Making Methodology. New Jersey: World Scientific, 2005. ISBN 9812386955.

[23] ŠIMONOVÁ, S. Identification of Data Content Based on Measurement of Quality of Performance. E+M Ekonomie a Management. 2012, Vol. 15, Iss. 1, pp. 128-138. ISSN 12123609.

[24] TSO. ITIL: Introduction to the ITIL Service Lifecycle. London: The Stationery Office, 2007. ISBN 978-0113310616.

[25] VOŘíŠEK, J., POUR, J., et al. Management podnikové informatiky. Praha: Professional Publishing, 2012. ISBN 978-80-7431-102-4.

[26] VOŘíŠEK, J., et al. Principy a modely rízení podnikové informatiky. Praha: Oeconomia, 2008. ISBN 978-80-245-1440-6.

[27] WEILL, P., ROSS, W.J. IT Governance: How top performers manage IT decision rights for superior results. Working Paper No.326. Boston: Harward Business School Press, 2004. 
[28] ŽÁK, M., et al. Konkurenční schopnost České republiky 2011-2012. Praha: Linde, 2013. ISBN 978-80-7201-910-6.

prof. Ing. Jiří Voříšek, CSc. University of Economics, Prague Faculty of Informatics and Statistics Department of Information Technologies Pan-European University, Bratislava Faculty of Informatics vorisek@vse.cz doc. Ing. Jan Pour, CSc. University of Economics, Prague Faculty of Informatics and Statistics Department of Information Technologies jan.pour@vse.cz

doc. Ing. Alena Buchalcevová, Ph.D. University of Economics, Prague Faculty of Informatics and Statistics Department of Information Technologies alena.buchalcevova@vse.cz 


\section{MANAGEMENT OF BUSINESS INFORMATICS MODEL - PRINCIPLES AND PRACTICES}

\section{Jiří Voříšek, Jan Pour, Alena Buchalcevová}

Increasing requirements on the extent and quality of business informatics management have resulted in a development of various methodologies, models, frameworks and standards (e.g. ITIL, COBIT, ISO 20000, etc.). These methodological sources represent current best practices and include recommendations addressing various IT management issues encountered in practice. However, their application in practice brings along numerous problems as showed by the results of recent surveys conducted among Czech organizations. Moreover, their use, in particular in small and medium sized enterprises, is still very limited. In this paper we discuss existing IT management approaches and their limitations with a particular focus on Czech organizations. We base our discussion on available literature, our surveys of Czech organizations and our experiences gained from practical assignments. The MBI (Management of Business Informatics) model developed at the Department of Information Technologies, University of Economics in Prague attempts to overcome such limitations of existing methodologies and models. We describe the basic concepts and features of the $\mathrm{MBI}$ model. The $\mathrm{MBI}$ model represents an original solution that brings along essential advantages over existing business informatics management methodologies. To such advantages primarily belong monitoring links between individual objects and the possibility to utilize these links as search criteria. Furthermore, the model captures an influence of various business informatics factors on the MBI tasks and enables to adjust its context according to these factors. In addition, the $\mathrm{MBI}$ model metrics and analytical applications monitor IT investment effectiveness. The MBI model is available as a web application (at website mbi.vse.cz) and the MBI community participates on its further development.

Key Words: Management of business informatics, methodologies and frameworks, cloud computing, performance measurement.

JEL Classification: M15, L10, L86.

DOI: 10.15240/tul/001/2015-3-014 